Bogotá, 5-6 de junio de 2014

\title{
Coloquio Internacional: «Nacionalismos y Educación en los países andinos: entre identidad y ciudadanía»
}

Bogotá, 5-6 de junio de 2014

\section{Chloé Paux}

\section{Q OpenEdition}

12 Journals

\section{Edición electrónica}

URL: http://journals.openedition.org/bifea/5304

DOI: $10.4000 /$ bifea.5304

ISSN: 2076-5827

Editor

Institut Français d'Études Andines

\section{Edición impresa}

Fecha de publicación: 1 agosto 2014

Paginación: 385-387

ISSN: 0303-7495

\section{Referencia electrónica}

Chloé Paux, « Coloquio Internacional: «Nacionalismos y Educación en los países andinos: entre

identidad y ciudadanía» », Bulletin de l'Institut français d'études andines [En línea], 43 (2) | 2014,

Publicado el 08 agosto 2014, consultado el 06 noviembre 2020. URL : http://journals.openedition.org/ bifea/5304; DOI : https://doi.org/10.4000/bifea.5304

\section{cc) (†)}

Les contenus du Bulletin de l'Institut français d'études andines sont mis à disposition selon les termes de la licence Creative Commons Attribution - Pas d'Utilisation Commerciale - Pas de Modification 4.0 International. 


\title{
COLOQUIO INTERNACIONAL: «NACIONALISMOS Y EDUCACIÓN EN LOS PAÍSES ANDINOS: ENTRE IDENTIDAD Y CIUDADANÍA»
}

\author{
Bogotá, 5-6 de junio de 2014
}

El 5 y 6 de junio de 2014, en el salón oval del Edificio de Posgrados de la Universidad Nacional de Colombia en Bogotá, se llevó a cabo el coloquio «Nacionalismos y Educación en los países andinos: entre identidad y ciudadanía»1 que reunió a 15 expositores, oriundos de los países andinos: Bolivia, Colombia, Ecuador y Perú, y a la vez de otros países como Francia, España, Reino Unido y Estados Unidos.

Organizado por las coordinadoras de los polos andinos del Instituto de las Américas (IdA), Cristina Moreno y Chloé Paux, el evento se realizó gracias al apoyo del Instituto Francés de Estudios Andinos (IFEA) y de la Embajada de Francia en Colombia, así como con el auspicio de la Universidad Nacional de Colombia, del Ministerio de Asuntos Exteriores y del Desarrollo Internacional (MAEDI) y del Centro Nacional para la Investigación Científica (CNRS).

La idea de este evento nace de una iniciativa conjunta de los polos andinos de Lima y Bogotá del Instituto de las Américas y es representativo de las estrechas colaboraciones que se han venido tejiendo entre las instituciones locales y el IdA. Tanto en su conceptualización y organización como en sus contenidos, fueron representadas diversas universidades de la región andina y de Europa.

La perspectiva regional y trasnacional que subyació a este evento se reflejó en su temática misma. El objetivo de este encuentro era el de hacer dialogar las diferentes investigaciones que en materia de construcción nacional y educación se han venido desarrollando en la región andina y, de esta manera, subrayar las relaciones plurales que tuvieron entre ellos. Aunque en muchos casos la voluntad de construir una identidad nacional haya pasado por una diferenciación frente a aquel considerado como «Otro», y en particular frente a sus vecinos próximos, la relación entre estos es sin lugar a duda más compleja.

1 El detalle de la programación y la información complementaria se encuentra en la página web del coloquio (www.nacionalismosandinos.jimdo.com) y pronto estará disponible la grabación del evento en el sitio web del Instituto de las Américas (www.institutdesameriques.fr). 
Los sistemas educativos modernos nacen en la región, y en el mundo, en estrecha relación con los procesos de construcción nacional. A través de la educación se buscó forjar una cultura política y una identidad cultural que estuvieran acorde a los paradigmas del Estado-nación. Identidad y ciudadanía son las dos caras de la problemática que motivaron estas jornadas de estudio. Ahora bien, y como lo muestran las diferentes investigaciones que aquí podrán encontrar, estos son conceptos variables según los contextos históricos, nacionales, políticos. Mapear históricamente los orígenes de los sistemas educativos, así como sus transformaciones, representa una clave para entender la configuración contemporánea de estos sistemas así como para evaluar las disyuntivas a las que se enfrentan los Estados en la actualidad.

Articulado alrededor de dos jornadas temáticas, el evento se abrió con palabras de bienvenida de las coordinadoras regionales del IdA y del responsable del

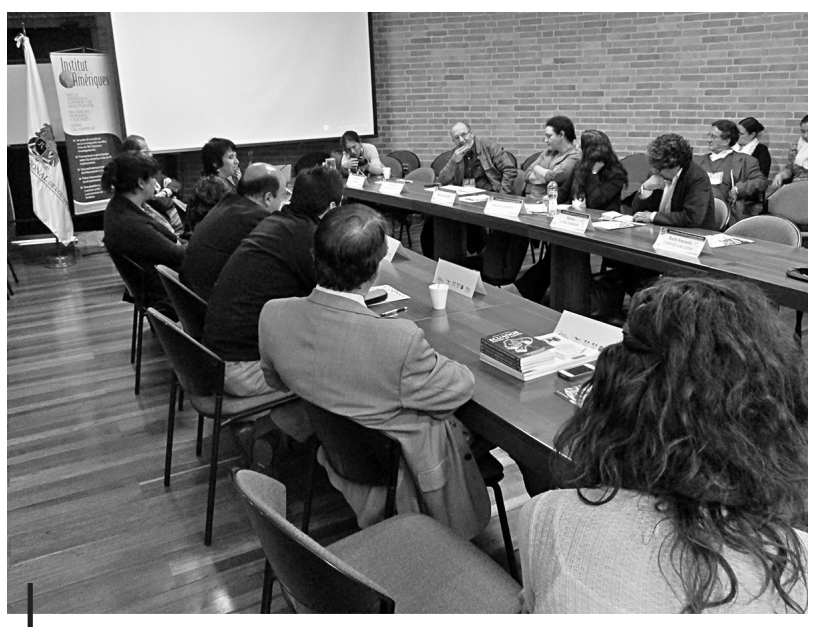

Conferencia del Dr. Enrique Ayala Mora, rector de la Universidad Andina Simon Bolívar, sede Ecuador: «Interculturalidad y plurinacionalidad, una disyuntiva en la enseñanza cívica» departamento de Sociología, William Beltran Cely, seguidas por una videoconferencia de Jean-Michel Blanquer, presidente del Instituto de las Américas. La conferencia inaugural estuvo a cargo del doctor Heraclio Bonilla, profesor emérito de la Universidad nacional que presentó una conferencia titulada: «La experiencia del Perú en torno al papel de la educación en la construcción nacional».

Durante esta primera jornada titulada «Construcción nacional y educación: un proyecto político-pedagógico» también se desarrollaron seis conferencias en las que se analizó la temática de la ciudadanía. Participaron a lo largo del día, el Dr. Alejandro Alvarez Gallego de la Universidad Pedagógica de Colombia; el Dr. Grover Antonio Espinoza de la Virginia Commonwealth University en Estados Unidos a través de una videoconferencia; el Dr. Milton Luna Tamayo, responsable nacional de Contrato Social por la educación en Ecuador; la Dra. Patricia Oliart de la Universidad de Newcastle que llegó desde el Reino Unido; la Dra. Natacha Vaisset de la Universidad de La Rochelle en Francia; así como la Dra. Ruth Amanda Cortes Salcedo del Instituto para la Investigación Educativa y el Desarrollo Pedagógico de Colombia.

La jornada «Construcción del relato nacional: elementos discursivos y figuras del Otro», llevada a cabo el segundo día, se enfocó en la problemática de la identidad, contando con la participación de siete conferencistas. Por la mañana, 
se desarrollaron las conferencias del Dr. Carlos Paladines de la Universidad técnica de Ambato en Ecuador, de la Dra. Elisabeth Castillo de la Universidad del Cauca en Colombia y del Dr. Enrique Ayala Mora, rector de la Universidad Andina Simon Bolívar sede Ecuador. Por la tarde intervinieron la Dra. Esther Aillon de la Universidad Mayor de San Andrés de Bolivia, el Dr. Matthias Vom Hau del Institut Barcelona d'Estudis Inetrnacionals (IBEI) (a través de una videoconferencia en vivo desde España), y el Dr. Raúl Antonio Bustos González de la Universidad de Tarapacá y Dr. Alfonso Diaz, decano de la facultad de Educación y Humanidades de la misma universidad en Chile, quienes dieron una conferencia común

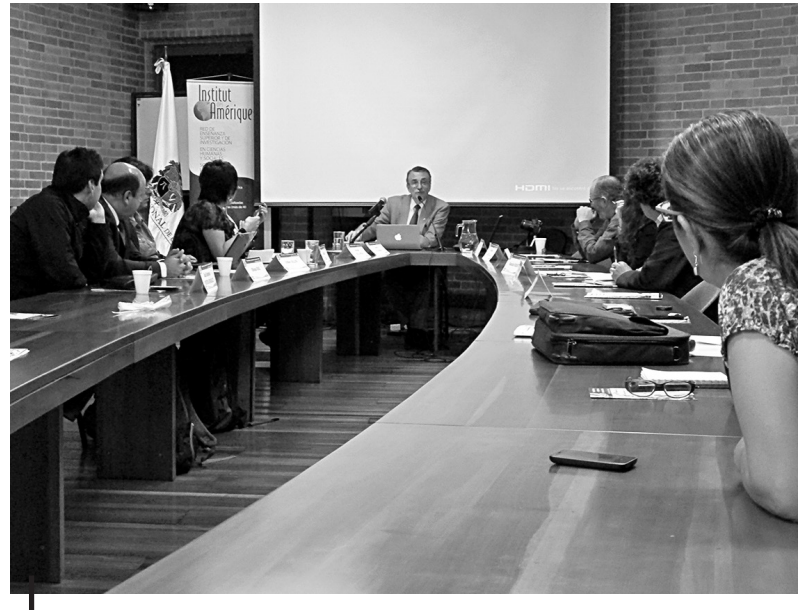

Intercambio entre los conferencistas durante el segundo día del coloquio para cerrar el día.

Las conferencias que brindaron los especialistas y los debates dinámicos que se desarrollaron durante el coloquio permitieron pensar las problemáticas a las que se enfrenta hoy en día la región, trátense de las dinámicas de integración regional, como de las tensiones entre los paradigmas nacionales y multiculturales, o entre diversas comprensiones de la ciudadanía política.

Si bien las conferencias dadas durante este encuentro científico resultaron ser de horizontes tanto geográficos como académicos distintos, pareció obvia la importancia de estudiar en paralelo los procesos de construcción nacional regionales a través de la herramienta que representó y sigue representando la Educación, pues, como lo subrayó Jean-Michel Blanquer durante su videoconferencia, estudiar la historia de la Educación es también estudiar la historia de la República.

Dado el acervo de la temática, la calidad de los debates que nacieron durante esos días y el entusiasmo con el cual fue recibido el evento, los conferencistas como las organizadoras mostraron su interés en mantener abierto el tema para un debate más amplio que podría dar el paso a la organización de otro evento en los próximos años. 